\title{
The effect of 5 different personalities on job stress in physical therapists
}

\author{
Eun Hyeong Kim ${ }^{a}$, Ho Young Jang ${ }^{b}$, Suk Min Lee ${ }^{c}$ \\ ${ }^{a}$ Department of Physical Therapy, Korean Redcross Gyeonggi-Incheon Regional Rehabilitation Hospital, Incheon, Republic of Korea \\ ${ }^{b}$ Department of Physical Therapy, The Catholic University of Korea, St. Paul's Hospital, Seoul, Republic of Korea \\ 'Department of Physical Therapy, College of Health Science and Social Welfare, Sahmyook University, Seoul, Republic of Korea
}

Objective: The purpose of this study was to investigate the effects of 5 different personalities on job stress in physical therapists. Design: Descriptive cross-sectional study.

Methods: Structured self-report questionnaires consisted of demographic items, 5 types of personalities, and occupational stress. A questionnaire was distributed to 420 physical therapists working in Seoul and Incheon who had voluntarily agreed to participate in the study after the purpose of the study was explained. Of the 420 questionnaires, 405 questionnaires were collected and showed a recovery rate of $96.4 \%$, of which 28 cases were excluded, leaving a total of 377 questionnaires being used for analyses. Pearson correlation analysis was performed to investigate the correlation of job stress and five personalities types. In addition, multiple regression analysis was performed to investigate the effect of general and occupational characteristics of physical therapist on job stress and the effect of personality type on occupational stress. All statistical significance levels were set at $p<0.05$.

Results: The highest number of subjects, which were the physical therapists, showed the tendency to have a sincere personality, followed by affinity, openness, extroversion, and neuroticism. Physical therapists reported to be the most stressed in the order of professional role conflict, overload of work, work relation with a physician and supervisor, interpersonal relationship with patient and caregiver. The higher the level of affinity and sincerity, the lower the amount of stress received by the therapist from the interpersonal relationships between the patient and caregivers. On the other hand, the greater the level of openness and sincerity, the lower the stress levels related to professional role conflict.

Conclusions: This study showed that the personality type and job stress of physiotherapists had a statistically significant effect. It is very important for physiotherapists to find their own way of coping with stress, which is satisfactory and appropriate for their job, because it is related not only to individual problems but also to the quality of patient care and medical services. Therefore, it is necessary to continue conducting research on how to relieve the stress levels of physical therapists according to their personality characteristics.

Key Words: 5 different personalities, Occupational stress, Physical therapists

\section{Introduction}

Recently, the medical environment has been making a lot of effort to improve the quality of medical services and to increase the satisfaction of patients as customers. This means that most medical institutions are demanding emotional labor similar to that of service workers [1].
Sociologist Hochschild (1983) defined emotional labor as emotional management to create expressions and behaviors that can be seen by a large number of others [2].

These emotional worker conditions also apply to physical therapists. The role and expectations of a physical therapist as an emotional worker is likely to be linked to job stress that occurs when there is an imbalance between organizational

Received: 20 November, 2018 Revised: 17 December, 2018 Accepted: 17 December, 2018

Corresponding author: Suk Min Lee (ORCID https://orcid.org/0000-0002-6062-956X)

Department of Physical Therapy, College of Health Science and Social Welfare, Sahmyook University, 815 Hwarang-ro, Nowon-gu, Seoul 01795, Republic of Korea

Tel: 82-2-3399-1632 Fax: 82-2-3399-1639 E-mail: leesm@syu.ac.kr

(c) This is an Open-Access article distributed under the terms of the Creative Commons Attribution Non-Commercial License (http://creativecommons.org/licenses/ by-nc/4.0) which permits unrestricted non-commercial use, distribution, and reproduction in any medium, provided the original work is properly cited.

Copyright $\odot 2018$ Korean Academy of Physical Therapy Rehabilitation Science 
goals and individual needs in relation to the job.

Occupational stress refers to a condition in which an organization's members are in an inappropriate state with the job environment and refers to a state in which the psychological, behavioral, and physiological conditions change during normal interaction [3]. In particular, physical therapists not only encounter the physical pain and disabilities of the patients but also often face prolonged periods of their patients' social and psychological disorders of depression, anxiety, anger, and emotional control [4].

In addition, the dual command structure of medical care and administration, excessive workload, increase of medical disputes, and intensifying competition among medical institutions suggest that the medical staff, such as physical therapists, are highly likely to receive high levels of emotional labor and job stress [5,6].

As for the interaction between the individual and the environment, Robbins defined the overall nature of the way an individual reacts and interacts with the outside, and Allport also defined a dynamic system that determines the individual's unique adaptation to the environment [7].This implies that the degree of stress experienced by the individual may be different depending on the person because it is influenced by the internal and external variables of the individual even if they are exposed to the same stress factors.

As a result, studies have been conducted to investigate the relationship between personality type and stress, and personality is closely related to not only stress but also subjective well-being [8], affecting job satisfaction and attitude toward customers [9].

Costa and McCrae have identified some characteristics that are common to all individuals, such as neuroticism, extraversion, openness to experience, culture, intellect, agreeableness, and conscientiousness and will to achieve, which have been recently categorized as five personality types [10].

In order to find appropriate stress coping strategies for individuals, studies are under way on job stress according to personality types considering various tendencies and criteria [11-14], but unfortunately they are focused on other general occupations or nurses, and studies including physical therapists are rare.

In order to manage the job stress of the physical therapist, it is necessary to identify the variables that may affect the stress of the physical therapist and to have an individual approach to the variables.

The purpose of this study was to compare the factors di- rectly affecting job stress by analyzing the effects of the physical therapists' personality types on their job stress.

\section{Methods}

\section{Subject and procedure}

This study used a structured self-administered questionnaire and consisted of 77 questions that consisted of 9 general questions, 50 questions on the five personality types, and 18 questions on occupational stress. All scales were used after the reliability and validity tests have been verified and after the preliminary investigations have been made.

From August 16, 2017 to September 6, 2017, the subjects were given a self-administered questionnaire consisting of questions related to demographic characteristics, five personality types, and occupational stress. After selecting the hospitals in Seoul and Incheon City, and appointing a visit date by phone, and after receiving approval by the supervising physical therapist, questionaires were distributed to 420 physcial therapists. Of the total 420 questionnaires, 405 questionnaires were collected and $96.4 \%$ were recovered. Of these, there were no answers on 28 questionnaires, leaving a final total of 377 completed questionnaires used for this study. This study was approved by the Institutional Review Board of the Sahmyook University (IRB no. 2-1040781AB-N-01-2017095HR) and informed consent was obtained.

\section{Five types of personality}

The International Personality Item Pool has been used by which classifies five types of personalities, including neuroticism, extroversion, openness to experience, affinity, and integrity. It is composed of 50 questions with 10 items per personality type. Each item is evaluated on a 5-point Likert scale from 'not at all (1 point)' to 'strongly agree (5 points)'. The sum of the scores of each item corresponding to each factor is divided by the number of items.

In the previous study, the internal consistency of the entire item was 0.86 , and the reliability was reported to be as high, with a Cronbach's $\alpha$ value of 0.78 and 0.89 [15].

In this study, Cronbach's $\alpha$ for neurosis was $0.884,0.849$ for extroversion, 0.771 for openness, 0.749 for affinity, and 0.764 for sincerity. Cronbach's $\alpha$ for the total number of items was 0.831 .

\section{Occupational stress}

The occupational stress assessment tool developed for nurses was created by $\mathrm{Kim}$ and $\mathrm{Ku}$ [16]. However, for this 
study, the items related to nursing were excluded and only the items relevant to physical therapists were included. Although the questionnaire consisted of 18 questions, a total of 11 items were used for the final analysis, which included 5 items related to workload, 2 items related toworking with physicians and supervisors, 3 items related to patients and caregivers, and two items related to professional role conflict. Each item was composed of 5 points on a Likert scale from 'not at all (1 point)' to 'strongly agree ( 5 points)' and it was calculated by dividing the sum of the scores of

Table 1. General and occupational characteristics $\quad(\mathrm{N}=377)$

\begin{tabular}{|c|c|c|c|}
\hline Item & Classification & $\begin{array}{l}\text { Frequency } \\
\text { (persons) }\end{array}$ & $\begin{array}{c}\text { Ratio } \\
(\%)\end{array}$ \\
\hline \multirow[t]{2}{*}{ Gender } & Male & 173 & 45.9 \\
\hline & Female & 204 & 54.1 \\
\hline \multirow[t]{3}{*}{ Age (y) } & $20-29$ & 233 & 61.8 \\
\hline & $30-39$ & 119 & 31.6 \\
\hline & Over 40 & 25 & 6.6 \\
\hline \multirow[t]{2}{*}{ Marital status } & Single & 279 & 74.0 \\
\hline & Married & 98 & 26.0 \\
\hline \multirow[t]{4}{*}{ Level of education } & Major college graduate & 126 & 33.4 \\
\hline & College graduate & 198 & 52.5 \\
\hline & $\begin{array}{l}\text { Attending graduate } \\
\text { school }\end{array}$ & 25 & 6.6 \\
\hline & $\begin{array}{l}\text { Graduated from graduate } \\
\text { school }\end{array}$ & 28 & 7.4 \\
\hline \multirow[t]{6}{*}{ Work place } & Private Clinic & 20 & 5.3 \\
\hline & $\begin{array}{l}\text { Nursing Home \& } \\
\text { rehabilitation hospital }\end{array}$ & 202 & 53.6 \\
\hline & Hospital & 56 & 14.9 \\
\hline & $\begin{array}{l}\text { General and university } \\
\text { hospital }\end{array}$ & 52 & 13.8 \\
\hline & $\begin{array}{l}\text { Public institutions and } \\
\text { public hospitals }\end{array}$ & 46 & 12.2 \\
\hline & Other & 1 & 0.3 \\
\hline \multirow[t]{3}{*}{ Hours of work } & Less than 8 hours & 7 & 1.9 \\
\hline & 8 hours & 300 & 79.6 \\
\hline & More than 8 hours & 70 & 18.6 \\
\hline \multirow[t]{3}{*}{ Work experience } & Less than 5 years & 214 & 56.8 \\
\hline & $\begin{array}{l}\text { More than 5-less than } 15 \\
\text { years }\end{array}$ & 145 & 38.5 \\
\hline & More than 15 years & 18 & 4.8 \\
\hline \multirow[t]{6}{*}{ Main work } & Neurology (adults) & 249 & 66.0 \\
\hline & Neurology (pediatrics) & 22 & 5.8 \\
\hline & Light and electrotherapy & 41 & 10.9 \\
\hline & $\begin{array}{l}\text { Sports and } \\
\text { musculoskeletal system }\end{array}$ & 56 & 14.9 \\
\hline & Hydrotherapy & 1 & 0.3 \\
\hline & Other & 8 & 2.1 \\
\hline \multirow[t]{2}{*}{ Employment type } & Full-time & 320 & 84.9 \\
\hline & Contract & 57 & 15.1 \\
\hline
\end{tabular}

each item corresponding to each factor by the number of items. The reliability of this research tool was found to be Cronbach's $\alpha 0.948$ in the previous study, and Cronbach's $\alpha$ 0.770 in the present study.

\section{Data analysis}

The collected data were analyzed by IBM SPSS Statistics 19.0 software (IBM Co., Armonk, NY, USA). A frequency analysis was conducted to examine general and occupational characteristics of physical therapists. In order to analyze the five personality types and job stress according to the general characteristics and occupational characteristics of physical therapists, the t-test and one-way ANOVA was conducted. Pearson correlation analysis was performed to investigate the correlation of job stress according to the five personality types.

In addition, multiple regression analysis was performed to investigate the effect of general and occupational characteristics of physical therapists and personality type on occupational stress. All statistical significance levels were set at 0.05 or less.

\section{Results}

General characteristics and occupational characteristics of subjects

The general characteristics and occupational characteristics of the subjects are shown in Table 1.

\section{Five types of subject personalities}

Physical therapists showed the highest tendency towards sincerity, followed by affinity, openness, extroversion, and neurosis (Table 2).

\section{Occupational stress of subjects}

Physical therapists were found to be most stressed with professional role conflicts. This was followed by stress re-

Table 2. Five types of personalities

$(\mathrm{N}=377)$

\begin{tabular}{|c|c|c|c|}
\hline Variable & Physical therapist & Maximum & Minimum \\
\hline Neuroticism & $29.09(7.07)$ & 48 & 11 \\
\hline Extroversion & $30.62(6.20)$ & 48 & 12 \\
\hline Openness & $31.79(4.91)$ & 47 & 13 \\
\hline Affinity & $33.60(5.02)$ & 48 & 15 \\
\hline Integrity & $34.35(5.17)$ & 49 & 18 \\
\hline
\end{tabular}

Values are presented as mean (SD) or number only. 
lated to workload, business relations with physicians and supervisors, and interpersonal relationships with patients and caregivers (Table 3 ).

\section{Relationship between the five personality types and oc- cupational stress}

Pearson correlation analysis was used to analyze the relationship between occupational stress and personality type. The results of the analysis are shown in Table 4.

There was a statistically significant correlation $(p<0.01)$ in neuroticism with all other types of occupational stress except for stress related to business relations with physicians

Table 3. Occupational stress

$(\mathrm{N}=377)$

\begin{tabular}{lccc}
\hline \multicolumn{1}{c}{ Variable } & $\begin{array}{c}\text { Physical } \\
\text { therapist }\end{array}$ & Maximum & Minimum \\
\hline $\begin{array}{l}\text { Full load } \\
\begin{array}{l}\text { Interpersonal relationships } \\
\text { with patients and }\end{array}\end{array}$ & $3.28(80)$ & 5.00 & 1.25 \\
$\begin{array}{l}\text { caregivers } \\
\begin{array}{l}\text { Conflicts in professional } \\
\text { roles }\end{array}\end{array}$ & $3.66(76)$ & 5.00 & 1.00 \\
$\begin{array}{l}\text { Work with physicians and } \\
\text { supervisors }\end{array}$ & $2.62(79)$ & 5.00 & 1.00 \\
\hline
\end{tabular}

Values are presented as mean (SD) or number only. and supervisors. Extroversion $(p<0.01, \mathrm{r}=-0.230)$ and openness $(p<0.01, \mathrm{r}=-0.309)$ was negatively correlated with professional role conflict, and affinity was negatively correlated with patient and guardian relationship stress $(p<0.01, \mathrm{r}=-0.221)$. In the case of integrity, it was negatively correlated with stress related to patients and guardian relationship $(p<0.01, \mathrm{r}=-0.238)$ and professional role conflict $(p<0.01, \mathrm{r}=-0.258)$.

\section{The effect of personality type on occupational stress}

Table 5 shows the differences among the four sub-domains of occupational stress according to the personality type of the study subjects.

Neuroticism ( $\beta=0.293, p<0.001$ ) was found to have a statistically significant effect on 'workload overload'. The total explanatory power of the workload of personality type was $8.9 \%$.

The relationship between the patient and the caregiver's interpersonal relationship showed that neuroticism ( $\beta=$ $0.307, p<0.001$ ), affinity ( $\beta=-0.132, p<0.05$ ), and sincerity ( $\beta=-0.123, p<0.05$ ) had a significant effect on the interpersonal relationship between the patient and the caregiver, and that neuroticism had a statistically significant effect, while affinity and integrity had negative effects. On the other hand, the total explanatory power of the personality

Table 4. Relationship between personality type and occupational stress

\begin{tabular}{lcccc}
\hline Personality type & Full load & $\begin{array}{c}\text { Business relations with a } \\
\text { physician and supervisor }\end{array}$ & $\begin{array}{c}\text { Relationship between } \\
\text { patients and caregivers }\end{array}$ & Conflicts in professional roles \\
\hline Neuroticism & $0.292^{* *}$ & 0.077 & $0.349^{* *}$ & $0.284^{* *}$ \\
Extroversion & -0.051 & 0.047 & $-0.162^{* *}$ & $-0.230^{* *}$ \\
Openness & -0.021 & 0.009 & $-0.106^{*}$ & $-0.309^{* *}$ \\
Affinity & -0.081 & -0.058 & $-0.221^{* *}$ & $-0.171^{* *}$ \\
Integrity & -0.074 & -0.045 & $-0.238^{* *}$ & $-0.258^{* *}$ \\
\hline
\end{tabular}

${ }^{*} p<0.05,{ }^{* *} p<0.01$.

Table 5. The effects of personality types on occupational stress

\begin{tabular}{|c|c|c|c|c|c|c|c|c|c|c|c|c|}
\hline \multirow{2}{*}{ Personality type } & \multicolumn{3}{|c|}{ Full Load } & \multicolumn{3}{|c|}{$\begin{array}{l}\text { Patient and caregiver } \\
\text { relationship }\end{array}$} & \multicolumn{3}{|c|}{ Conflicts in professional roles } & \multicolumn{3}{|c|}{$\begin{array}{l}\text { Business relations with a } \\
\text { physician and supervisor }\end{array}$} \\
\hline & $\beta$ & $p$ & $\mathrm{R}^{2}$ & $\beta$ & $p$ & $\mathrm{R}^{2}$ & $\beta$ & $p$ & $\mathrm{R}^{2}$ & $\beta$ & $p$ & $\mathrm{R}^{2}$ \\
\hline Neuroticism & 0.293 & 0.000 & 0.089 & 0.307 & 0.000 & 0.168 & 0.210 & 0.000 & 0.174 & 0.077 & 0.148 & 0.004 \\
\hline Extroversion & 0.001 & 0.980 & & -0.037 & 0.515 & & -0.085 & 0.131 & & 0.101 & 0.100 & \\
\hline Openness & 0.044 & 0.427 & & 0.033 & 0.537 & & -0.200 & 0.000 & & 0.015 & 0.791 & \\
\hline Affinity & -0.059 & 0.719 & & -0.132 & 0.019 & & -0.008 & 0.051 & & -0.090 & 0.139 & \\
\hline Integrity & -0.002 & 0.794 & & -0.123 & 0.022 & & -0.124 & 0.020 & & -0.027 & 0.646 & \\
\hline
\end{tabular}


type on interpersonal relationships of the patients and caregivers was $16.8 \%$.

Stress exists due to 'Professional role conflict' in which neuroticism $(\beta=0.210, p<0.001)$, openness $(\beta=-0.200$, $p<0.001$.), and sincerity $(\beta=-0.124, p<0.05)$ have a significant effect on professional role conflict. On the other hand, the total explanatory power of the personality type on conflict of professional role was $17.4 \%$.

\section{Discussion}

In a previous study on job stress of physical therapist, the work stress of physical therapists was found to be due to 'role ambiguity' and 'excessive role' in the study of Huh [17]. In this study, 'role ambiguity' was defined as 'professional role conflict' and 'role overload' which was similar to 'workload overload'. This indicates that even after 15 years of previous research, clinical physical therapists are still under stress in similar areas.

The most significant factors of 'professional role conflict', which was the main occupational stress of physical therapists, were final education $(8.6 \%)$, age $(8.5 \%)$, marital status $(6.1 \%)$, career $(5.9 \%)$, gender $(5.5 \%)$, contract work $(0.4 \%)$, and the most significantly stressed group was unmarried women in their twenties who had graduated from college and had less than five years of experience.

In regards to physical therapists in their twenties having high level of stress, there is partial match in results by Song Young Hwa's study (1990) called 'The study on the amount of physical therapist stress levels and exhaustion and experience status' where it was stated that the lesser amount of years of work experience and age, the greater the degree of exhaustion was experienced, and a study by Koh and Kim [18] stating that the lower the age, the lesser the person experienced a sense of achievement.

The effects of personality type on professional role conflict were significant with neuroticism, sincerity and openness. As the nature of neuroticism does not allow stable and comfortable work, it also makes a person feel uneasy and depressed about their work and identity [12]. As the quality of work is lowered, resulting in doubts about the conflict of professional roles and more stress, which is the result of a static effect.

Considering that the group with a high tendency in neuroticism was 20 -year-old unmarried physical therapists with less than 5 years experience, it was predicted that work performance was less proficient and was further influenced by neurotic symptoms. Openness tends to not only promote creativity but also intellectual curiosity and logical and analytical thinking [12]. It is considered that those who have lower levels of stress in regards to professional role conflicts may be because rather than being merely stressed due to lack of skill or knowledge, they are more likely to resolve this issue through direct academic inquiry, they have integrity and have respect for the values and customs of the established society, and strongly consider themselves to be a self-competent and well-adjustable person [12].

The second most significant cause of occupational stress was having a full work load, where it was significantly affected by certain variables, such as marital status (14.1\%), weekly workload $(5.8 \%)$, age $(4.3 \%)$, gender $(3.1 \%)$ and less than five years of experience $(2.9 \%)$. The most stressful group were unmarried female physical therapists who were responsible for the light and electrotherapy, and with less than 5 years experience. In regards to personality type, the higher the level of neuroticism, the higher the level of workload-related stress. A younger, beginning physiotherapist may exhibit passion and energy but may feel psychological exhausted and mentally fatigued by experiencing the difference between theory and practice [19].

Stress related to 'working with physicians and supervisors' indicates either that the physician's orders are not appropriate for the patient or there is a negative relationship between the therapist and the physician or supervisor. In this study, regression analysis showed that marital status had a significant effect on stress related to work with physicians and supervisors, and the explanatory power was $1.3 \%$.

There was a difference in occupational stress levels between general and professional characteristics, and therapists who worked at a general hospital and rehabilitation hospital, those who had greater than 5 years but less than 15 years of experience, those who were attending graduate school, were married, and in their thirties were reported to have the greatest level of stress.

On the other hand, it is considered that therapists who were in their forties had less stress because with increase in age, they have developed sufficient treatment skills, social stability, and various exeriences and flexibility with others [20].

The variables that have the most significant effect on 'interpersonal relationship with patients and caregivers' were significant differences according to gender, age, marital status, place of work, and career experience, particularly in unmarried, female physical therapists in their twenties 
with less than 5 years of experience, and regression analysis results showed that the main variables affecting the actual work were business $(7.2 \%)$, age $(2.9 \%)$, gender $(2.7 \%)$, marital status $(2.5 \%)$, and work experience $(1.7 \%)$, respectively, which all generally had a low impact. On the other hand, the effect of personality type on stress was higher when neuroticism was higher, and stress levels were lower when affinity and sincerity levels were higher. The explanatory power of the effect of these personality factors on stress levels was $16.8 \%$, indicating that these factors were the most influential factors compared to the others.

Physical therapists are often faced with the not only the the physical pain and disability of their patients, but also their depression, anxiety, anger, and social and psychological impairments of emotional control, due to the nature of their occupation [4,21]. Therefore, physical therapists are asked to provide a sense of security and trust for patients with anxiety and irritability during the course of their treatment.

Because this was a cross-sectional study, there is a limitation in explaining the causal relationship between personality type and job stress. Since it is limited to Seoul and Incheon, the results cannot be generalized to all physical therapists. However, this study was able to assess and statistically compare the current state of job-related stress in the clinic and confirm that personality types does affect the level of job stress. These results may be used as a background as a method of finding a solution related to this problem.

Future studies shoud require continuous research in order to alleviate these limitations, and take into account the personality traits of physical therapists on job-related stress.

\section{Conflict of Interest}

The authors declared no potential conflicts of interest with respect to the authorship and/or publication of this article.

\section{References}

1. Kim HJ, Lee BW, Hwang JH, Lee MS, Na BJ, Lee JY. The level of emotional labor among workers in one university hospital. J Health Adm 2012;22:129-44.

2. Jeong MG, Lim HC, Choi HS. Study of consequences of employees`emotional labor in call centers. J Korea Serv Manag Soc 2008;9:319-45.

3. Park EY, Kim EJ. Job stress and self-efficacy of occupational therapist. Korea Content Soc 2008;8:208-16.

4. You YY, Ann CS. A study of the relationships between perceived rehabilitation - motivation and quality of life in patients after a cerebrovascular accident. J Korean Soc Occup Ther 2009;17: $1-16$.

5. Ko JW, Seo YJ, Park HY. The effect of job stress and social support on the organizational effectiveness of hospital employees. Korean J Prev Med 1996;29:295-308.

6. Jo SG, Park MS. The influence of emotional labor and job stress on somatization symptoms among nurse officers. J Mil Nurs Res 2013;31:77-90.

7. Im SB, Kim KE. Clinical nurses' job stress and coping strategies according to personality type. J Korean Acad Psychiatr Ment Health Nurs 2005;14:390-9.

8. Malkoç A. Big five personality traits and coping styles predict subjective well-being: a study with a Turkish sample. ProcedSoc Behav Sci 2011;12:577-81.

9. Kim JJ, Jeon HS. A study on employee satisfaction and customer-oriented attitudes using a 5-factor model. AIK Spring Conference 2010:491.

10. Kim MK, Kim JG. A study on the coping strategy for job stress and job satisfaction from the personality type of hotel employees. Korea Tour Res Assoc 2012;26:515-33.

11. Hwang JH. Job stress in teaching and the way of stress coping according to MBTI personality type of the kindergarten teacher [Master thesis]. Seoul: Myongji University; 2008.

12. Kim SY. The relationship between the Big Five personality types and emotional intelligence and social abilities of elementary school students [thesis]. Seoul: Ewha Women's University; 2011.

13. Lee DY, Koo YB. A study on the junior college librarians personality type and job satisfaction. J Korean Libr Inf Sci Soc 2008; 39:119-37.

14. Han AK, Kim OS, Won JS. A study on job stress and coping method by the personality types of clinical nurses. J Korean Clin Nurs Res 2007;13:125-136.

15. Kim YR. The relationship between the fivetypes of physical therapy majors and the satisfaction of a major and the academic performance guide [thesis]. Seoul: Samyook University; 2012.

16. Kim MJ, Ku MO. The development of the stresses measurement tool for staff nurses working in the hospital. J Korean Acad Nurs 1984;12:28-37

17. Huh YB. Job stress of physical therapists and organizational effectiveness [Master thesis]. Busan: Inje university 2002.

18. Koh EH, Kim KW. The study on the experience of the burnout and the type of coping of the child counselor. Korean Assoc Play Ther 2001;4:3-14.

19. Lee JH. Relationship between self-efficacy and perceived social support, burnout of play therapist. [Master thesis]. Seoul: SeoulWomen's University; 2006.

20. Kim KW, Choi MS, Kim HJ. Study on the ego-resiliency, the stress coping style according to the career, the training experience of child counselor. Korean J Hum Dev 2005;12:1-18

21. Kim HG, Oh KJ. Post stroke depression a review on it's prevalence, course and relation to lesion location. Korean J Clin Psychol 1996;15:217-34. 